\title{
Níveis Dietéticos de Lisina para Suínos da Raça Landrace dos 15 aos 30 kg$^{1}$ \\ Valéria Moretto², Juarez Lopes Donzele ${ }^{3}$, Rita Flávia Miranda de Oliveira $^{3}$, Dalton de Oliveira Fontes ${ }^{2}$
}

\begin{abstract}
RESUMO - Com o objetivo de determinar a exigência nutricional de lisina total para suínos da raça Landrace, machos inteiros e fêmeas, de 15 a $30 \mathrm{~kg}$ de peso, foram conduzidos dois experimentos. Utilizaram-se 50 fêmeas no experimento I e 50 machos inteiros no experimento II, em delineamento em blocos casualizados, com cinco tratamentos, cinco repetições e dois animais por unidade experimental, em cada experimento. Os tratamentos consistiram de uma ração basal suplementada com cinco níveis de L-lisina.HCl, resultando em rações com 0,$85 ; 0,95 ; 1,05 ; 1,15 ;$ e $1,25 \%$ de lisina, em ambos os experimentos. No experimento I, o consumo de ração médio diário não foi influenciado pelo nível de lisina das rações. Ganho de peso médio diário, consumo de lisina médio diário e taxa de deposição de proteína na carcaça aumentaram de forma linear com o nível de lisina da ração. Os tratamentos influenciaram de forma quadrática a conversão alimentar, que melhorou até o nível de $1,08 \%$ de lisina. No experimento II, os tratamentos não influenciaram o consumo de ração médio diário e a conversão alimentar. Constatou-se efeito quadrático dos níveis de lisina sobre ganho de peso médio diário, consumo de lisina médio diário e taxa de deposição de proteína na carcaça. Os melhores resultados de ganho de peso foram observados no nível de 1,08\% de lisina. A exigência de lisina total na ração, para a fase inicial de desenvolvimento (15 a $30 \mathrm{~kg}$ ), foi de 1,08\%, para ambos os sexos.
\end{abstract}

Palavras-chave: lisina, suínos, fase inicial, Landrace

\section{Dietary Lysine Levels for Landrace Pigs from 15 to $30 \mathrm{~kg}$}

\begin{abstract}
Two experiments were carried out to determine the total lysine requirement of purebred Landrace swine, males and females, from 15 to $30 \mathrm{~kg}$ live weights. Fifty females and fifty males were used in a randomized complete block design, with five treatments, five replications and two animals per experimental unit, in the experiments I and II, respectively. The treatments consisted of a basal diet, supplemented with five levels of L-lysine.HCL, resulting in diets with $.85, .95,1.05,1.15,1.25 \%$ of total lysine in both experiments. In experiment I, the dietary lysine levels did not influence the average daily feed intake. The average daily gain, daily lysine intake and protein deposition rates in the carcass linearly increased with the lysine level. The treatments quadractily influenced the feed:gain ratio, which improved up to $1.08 \%$ lysine level. In the experiment II, lysine level did not influence the average daily feed intake and the feed:gain ratio. There was a quadratic effect of dietary lysine level on average daily gain, average daily lysine intake and protein deposition rate in the carcass. The best results of average weight gain were obtained with the level of $1.08 \%$ lysine. The total lysine requirement, for the starting growing phase ( 15 to $30 \mathrm{~kg}$ ), was estimated to be $1.08 \%$, for both sexes.
\end{abstract}

Key Words: Landrace, lysine, starting phase, swine

\section{Introdução}

Em virtude de a lisina ser o primeiro aminoácido limitante nas rações à base de cereais, para suínos em crescimento (COSGROVE et al., 1985; YEN et al., 1986), as respostas de desempenho e composição de carcaça dos animais podem estar associadas ao seu nível na dieta. Conseqüentemente, a determinação da exigência desse aminoácido seria necessária para definir os padrões de alimentação dos animais.

Muitas pesquisas têm sido conduzidas na tentativa de estabelecer as exigências nutricionais de lisina para suínos nas fases inicial e de crescimento. No entanto, variações nas recomendações foram observadas também entre tabelas de exigências nutricionais de suínos.

Os diferentes valores encontrados, referentes às exigências de lisina dos suínos, revelaram que a exigência desse aminoácido é influenciada por vários fatores, como estádio fisiológico do animal, nível de consumo (EASTER e BAKER, 1980) e diferenças na composição da ração (MARTINEZ e KNABE, 1990). De acordo com Baker (1986), citado por HAHN et al. (1995), os fatores genéticos, o sexo, a

\footnotetext{
${ }^{1}$ Parte do trabalho de tese de Mestrado do primeiro autor. Projeto financiado pela FAPEMIG.

2 Estudante de Pós-Graduação DZO - UFV.

3 Professor do DZO-UFV.

${ }^{4}$ Professor da Escola de Veterinária - UFMG.
} 
concentração de energia ou proteína bruta na ração, a disponibilidade de lisina nos ingredientes e as condições ambientais também influem na determinação da exigência de lisina para suínos.

Considerando-se que entre sexos existem diferenças no consumo, na taxa e na eficiência de crescimento (HANSEN e LEWIS, 1993), pode-se inferir que a exigência de lisina deve ser estabelecida por categoria animal. No entanto, as tabelas de exigências nutricionais de suínos, tanto a brasileira (ROSTAGNO et al., 1992) como as estrangeiras (AGRICULTURAL RESEARCH COUNCIL - ARC, 1981; NATIONAL RESEARCH COUNCIL - NRC, 1998), não têm levado em consideração as diferenças nos níveis nutricionais entre os sexos.

Este trabalho foi realizado com o objetivo de avaliar níveis de lisina para suínos, machos inteiros e fêmeas, da raça Landrace, dos 15 aos $30 \mathrm{~kg}$ de peso.

\section{Material e Métodos}

Os experimentos foram conduzidos na Granja Núcleo de Suínos da Empresa de Pesquisa Agropecuária de Minas Gerais (EPAMIG), localizada na Fazenda Experimental do Vale do Piranga, no município de Oratórios, Minas Gerais, no período de março a junho de 1997.

No experimento 1, foram utilizadas 50 leitoas da

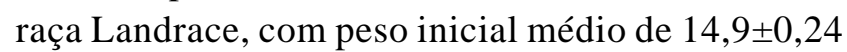
$\mathrm{kg}$ e idade inicial média de $49 \pm 3$ dias, e no experimento II 50 leitões com peso inicial médio de $15,0 \pm 0,33 \mathrm{~kg}$ e idade inicial média de 51 dias.

O delineamento experimental utilizado, em ambos os experimentos, foi o de blocos casualizados, com cinco tratamentos (níveis de lisina), cinco repetições e dois animais por unidade experimental. Foram adotados como critério, na formação dos blocos, o parentesco e o peso inicial dos animais.

Em cada experimento, os animais foram alojados em baias de alvenaria com piso de concreto, cobertas com telhas de cimento amianto, providas de comedouros semi-automáticos e bebedouros automáticos tipo chupeta.

As variações de temperatura foram registradas por meio de termômetro de máxima e mínima, instalado na parte interna mediana do galpão experimental. As temperaturas ambientais, máxima e mínima, médias, durante ambos os experimentos, foram $25,7 \pm 8,3$ e $13,5 \pm 7,5^{\circ} \mathrm{C}$, respectivamente.

Os tratamentos consistiram de uma ração basal, isoprotéica e isocalórica (Tabela 1), formulada à base de milho e farelo de soja, atendendo às exigências nutricionais dos animais em proteína, energia, cálcio, fósforo e sódio, preconizadas por ROSTAGNO et al. (1992), e suplementada com cinco níveis de L-lisina. $\mathrm{HCl}(0,00 ; 0,13 ; 0,26 ; 0,38$; e $0,51 \%)$, resultando em rações com 0,$85 ; 0,95 ; 1,05 ; 1,15 ;$ e $1,25 \%$ de lisina total. Água e ração foram fornecidas à vontade, em ambos os experimentos.

As análises bromatológicas dos ingredientes das rações e dos teores de proteína, gordura e matéria seca das carcaças foram realizadas no Laboratório de Nutrição Animal do Departamento de Zootecnia da UFV, de acordo com a metodologia descrita por SILVA (1990).

As variáveis estudadas foram: ganho de peso médio diário, consumo de ração médio diário, conversão alimentar, consumo de lisina médio diário e taxa de deposição de proteína na carcaça.

Tabela 1 - Composição da ração basal (\%)

Table 1 - Composition of the basal diet

\begin{tabular}{lr}
\hline $\begin{array}{l}\text { Ingredientes } \\
\text { Ingredients }\end{array}$ & $\begin{array}{r}\text { Ração basal } \\
\text { Basal diet }\end{array}$ \\
\hline Milho (Corn) & 67,20 \\
Farelo de soja (Soybean meal) & 23,00 \\
Glúten de milho (Corn gluten meal) & 3,60 \\
Óleo de soja (Soybean oil) & 1,51 \\
BHT & 0,01 \\
Bac-zinco 15\% (Zinc bacitracin 15\%) & 0,05 \\
Calcário(Limestone) & 0,04 \\
Núcleo 1 (Nucleus) & 4,00 \\
Inerte (Inert) & 0,59 \\
L-lisina.HCl (98\%) (L-lysine HCl) & 0,00 \\
Composição calculada (Calculated composition) & \\
Energia digestível (kcal/kg)(Digestible energy) & 3400 \\
Proteína bruta (Crude protein) & 17,7 \\
Ca(\%) & 0,75 \\
Fósforo total (Total phosphorus) & 0,57 \\
Na (\%) & 0,19 \\
Lisina total (Total lysine) & 0,85 \\
Lisina digestível (Digestible lysine) & \\
Metionina + cistina (Methionine + cystine) & 0,73 \\
Treonina (Threonine) & 0,64 \\
\hline
\end{tabular}

${ }^{1}$ Quantidade/kg (Amount/kg): Ca, $160 \mathrm{~g} ; \mathrm{P}, 80 \mathrm{~g} ; \mathrm{Na}, 46,3 \mathrm{~g} ; \mathrm{Fe}, 60.000 \mathrm{mg}$; Cu, 6250 mg; Mg, 1560 mg; Zn, 6250 mg; Co, 33 mg; I, 59 mg; Se, 10 mg; Flúor (Fluorine), 0,80 g; Vit. A, 360.000 Ul; Vit. $D_{3}, 75.000 \mathrm{UI}$; Vit. E, $4500 \mathrm{mg}$; Vit. K $3,180 \mathrm{mg}$; Tiamina (Thiamin), $120 \mathrm{mg}$; Riboflavina (Riboflavin), $240 \mathrm{mg}$; Piridoxina (Pyridoxin), 120 mg; Vit. $\mathrm{B}_{12}, 960 \mathrm{mg}$; Niacina (Niacine), $1125 \mathrm{mg}$; Ácido pantotênico (Pantothenic acid), $450 \mathrm{mg}$; Ácido fólico (Folic acid), $30 \mathrm{mg}$; Biotina (Biotin), $7500 \mathrm{mg}$; Colina (Choline), $12.500 \mathrm{mg}$; e Vit. C, $3000 \mathrm{mg}$.

2 Coeficiente médio de digestibilidade ileal verdadeira utilizado para lisina de $85,6 \%$, segundo RHÔNE-POULENC ANIMAL NUTRITION (1993).

2 Average coefficient of true ileal digestibility used for lysine was $85.6 \%$, according to RHÔNE-POULENCANIMAL NUTRITION (1993). 
Os dados de desempenho foram determinados mediante pesagem dos animais, das rações fornecidas e das respectivas sobras, até o final dos períodos experimentais, quando os animais atingiram peso médio de $31,7 \pm 1,63$ e de $31,3 \pm 1,82 \mathrm{~kg}$, nos experimentos I e II, respectivamente. A duração média de cada bloco, em ambos os experimentos, foi de $23 \pm 2,3$ dias.

Ao final do período experimental, após jejum de 24 horas com as últimas 12 horas de jejum hídrico, cinco animais, um de cada repetição por tratamento, foram abatidos por sangramento, depilados e eviscerados. As carcaças inteiras foram pesadas e as meia-carcaças, armazenadas em câmara fria e, posteriormente, trituradas em "cutter" comercial de $30 \mathrm{HP}$ e 1775 revoluções por minuto. Após homogeneização, foram retiradas amostras de aproximadamente $1,0 \mathrm{~kg}$, as quais foram conservadas a $-12^{\circ} \mathrm{C}$, para posteriores análises. Nos experimentos I e II, um adicional de cinco animais, com peso médio de $15,0 \pm 0,36 \mathrm{~kg}$ e $15,3 \pm 0,23 \mathrm{~kg}$, respectivamente, foi abatido para determinação da composição da carcaça no início do experimento.

No preparo das amostras, o material foi submetido à pré-secagem, em estufa com ventilação forçada a $60^{\circ} \mathrm{C}$, por 96 horas, seguida de pré-desengoduramento pelo método a quente, por quatro horas, em extrator tipo "SOXHLET". As amostras pré-secas e prédesengorduradas foram moídas, em moinho de bola, e acondicionadas, em vidros, para análises posteriores.

A água e a gordura retiradas inicialmente no preparo das amostras foram consideradas para correções dos valores das análises subseqüentes.

As taxas de deposição de proteína e gordura nas carcaças foram calculadas comparando-se as composições das carcaças dos animais do início com aquelas do fim do período experimental.

As variáveis de desempenho e as taxas de deposição de proteína e gordura nas carcaças foram analisadas utilizando-se o programa computacional SAEG (Sistema para Análises Estatísticas e Genéticas), desenvolvido pela UNIVERSIDADE FEDERAL DE VIÇOSA-UFV (1982).

A estimativa da exigência de lisina, para ambos os sexos, foi realizada por intermédio dos modelos de regressão linear e quadrático. A exigência de lisina digestível foi calculada considerando-se o coeficiente de digestibilidade verdadeira da lisina da ração basal de $85,6 \%$, de acordo com RHÔNEPOULENC ANIMAL NUTRITION (1993) e a da lisina sintética adicionada, de $100 \%$.

\section{Resultados e Discussão}

\section{Experimento I - fêmeas}

Os resultados de desempenho, consumo de lisina médio diário e taxa de deposição de proteína média diária, nas carcaças das leitoas, são apresentados na Tabela 2. Os níveis de lisina na ração proporcionaram aumento linear $(\mathrm{P}<0,05)$ do ganho de peso médio diário (GPMD) dos animais (Tabela 3 ).

Analisando-se a variação ocorrida no GPMD entre os diferentes tratamentos, constatou-se que, embora tenha ocorrido melhora linear, somente entre os níveis de 0,85 e $0,95 \%$ o aumento foi expressivo, representando $10,8 \%$, enquanto a partir desse nível o acréscimo não ultrapassou a $1,8 \%$. Pela análise deste resultado, pode-se inferir que a exigência para ganho de peso foi atendida no nível de $0,95 \%$ de lisina total, correspondente a $0,83 \%$ de lisina digestível. COELHO et al. (1991) também observaram aumento linear no ganho de peso de suínos de 10 a $20 \mathrm{~kg}$ de peso, em razão do incremento do nível de lisina na ração, que variou de 0,70 a $1,10 \%$. No entanto, em várias pesquisas (COELHO et al., 1987b; HARRISON et al., 1990; e SOUZA, 1997), não se verificou efeito do nível de lisina da ração no desempenho de suínos na fase inicial de desenvolvimento.

Não se observou efeito dos tratamentos sobre o consumo de ração, apesar de a variação no nível de lisina ter ocasionado, em determinados níveis, imbalanço de aminoácidos, pela deficiência ou pelo excesso de lisina, em relação ao perfil de aminoácido da ração basal. Este resultado pode ter ocorrido pelo fato de as rações experimentais serem isocalóricas.

Resultados de diversas pesquisas (COELHO et al., 1987b; LIMA et al., 1990; HARRISON et al., 1990; COELHO et al., 1991; e SOUZA, 1997) indicaram que suínos na fase inicial de desenvolvimento não tiveram seu consumo de ração influenciado pela variação no nível de lisina da ração.

Constatou-se efeito quadrático $(\mathrm{P}<0,05)$ dos tratamentos sobre a conversão alimentar (CA) (Tabela 3), que melhorou até o nível de 1,08\% de lisina total, correspondente a $0,96 \%$ de lisina digestível verdadeira. A melhora na eficiência de utilização da ração até o nível de $1,08 \%$ de lisina pode ter ocorrido em razão da melhora gradativa do balanceamento dos aminoácidos da ração, quando se elevou a concentração de lisina até aquele nível. Nesse nível de lisina total $(1,08 \%)$, a relação entre os aminoácidos metionina+cistina, treonina e triptofano e a lisina foi de 59, 66 e 20\%, respectivamente. Estes resultados 
MORETTO et al.

Tabela 2 - Desempenho, consumo de lisina e taxas de deposição de proteína na carcaça de suínos de 15 a 30 kg PV, alimentados com rações contendo níveis crescentes de lisina

Table 2 - Performance, lysine intake and protein deposition rate in carcass of swines from 15 to $30 \mathrm{~kg} L W$ fed diets with crescent levels of lysine

Características

Parameters Nível de lisina (\%)

Lysine level

$\mathrm{CV}$

Ganho de peso médio (g/dia)

Average weight gain

$$
\text { Fêmeas }{ }^{1} \text { (females) }
$$

$\operatorname{Machos}^{2}$ (males)

\begin{tabular}{|c|c|c|}
\hline 0,85 & 0,95 & 1,05 \\
\hline
\end{tabular}

\begin{tabular}{|c|c|c|}
\hline 0,85 & 0,95 & 1,05 \\
\hline
\end{tabular}

1,25

Consumo de ração médio (g/dia)

Average feed intake (g/day)

$\begin{array}{lllllll}\text { Fêmeas (females) } & 1407 & 1511 & 1409 & 1480 & 1544 & 6,20 \\ \text { Machos (males) } & 1336 & 1323 & 1415 & 1438 & 1321 & 4,66\end{array}$

Conversão alimentar

Feed:gain ratio

$\begin{array}{lllllll}\text { Fêmeas }^{2} \text { (females) } & 1,89 & 1,85 & 1,73 & 1,76 & 1,84 & 5,92 \\ \text { Machos (males) } & 1,97 & 1,88 & 1,81 & 1,83 & 1,90 & 7,27\end{array}$

Consumo de lisina médio ( $\mathrm{g} / \mathrm{dia})$

Average lysine intake ( $g /$ day)

$\begin{array}{lllllll}\text { Fêmeas (females) } & 3 \\ \text { Machos (males) }^{2} & 12 & 14 & 15 & 17 & 19 & 6,24 \\ & 11 & 13 & 15 & 17 & 17 & 4,72\end{array}$

Taxas de deposição de proteína médias na carcaça (g/dia)

Average protein deposition rate in carcass (g/day)

$\begin{array}{lllllll}\text { Fêmeas }{ }^{3} \text { (females) } & 75 & 88 & 86 & 93 & 92 & 10,77 \\ \text { Machos }^{4} \text { (males) } & 74 & 80 & 81 & 78 & 69 & 12,74\end{array}$

1 e 3 Efeito linear $(P<0,05$ e $P<0,01$, respectivamente) ([Linear effect $(P<.05$ and $P<.01$, respectively]).

2 e 4 Efeito quadrático $(P<0,05$ e $P<0,01$, respectivamente) (Quadratic effect $([P<.05$ and $P<.01$, respectively]).

Tabela 3 -Regressão dos efeitos dos níveis de lisina da ração

Table 3 - Regression of the effects of dietary lysine levels

\begin{tabular}{|c|c|c|}
\hline $\begin{array}{l}\text { Variáveis } \\
\text { Variables }\end{array}$ & $\begin{array}{l}\text { Regressão } \\
\text { Regression }\end{array}$ & \\
\hline \multicolumn{3}{|l|}{ Ganho de peso } \\
\hline $\begin{array}{l}\text { Fêmeas (Females) } \\
\text { Machos (Males) }\end{array}$ & $\begin{array}{l}\hat{Y}=603,362+213,203 \text { LIS } \\
\hat{Y}=-1564,38+4342,89 \text { LIS }-2017,46 \text { LIS }^{2}\end{array}$ & $\begin{array}{l}r^{2}=0,70 \\
r^{2}=0,72\end{array}$ \\
\hline $\begin{array}{l}\text { Conversão alimentar } \\
\text { Feed:gain ratio }\end{array}$ & & \\
\hline $\begin{array}{l}\text { Fêmeas (Females) } \\
\text { Consumo de lisina }\end{array}$ & $\hat{Y}=5,03117-6,07275 \mathrm{LIS}+2,8115 \mathrm{LIS}^{2}$ & $r^{2}=0,85$ \\
\hline $\begin{array}{l}\text { Fêmeas (Females) } \\
\text { Machos (Males) }\end{array}$ & $\begin{array}{l}\hat{Y}=-2,738+17,36 \text { LIS } \\
\hat{Y}=-22,5346+56,7554 \text { LIS - 20,2286LIS }\end{array}$ & $\begin{array}{l}r^{2}=0,97 \\
r^{2}=0,96\end{array}$ \\
\hline $\begin{array}{l}\text { Deposição proteína carcaç } \\
\text { Carcass protein deposition }\end{array}$ & & \\
\hline $\begin{array}{l}\text { Fêmeas (Females) } \\
\text { Machos (Males) }\end{array}$ & $\begin{array}{l}\hat{Y}=47,2691+37,4881 \mathrm{LIS} \\
\hat{Y}=-190,596+522,348 \mathrm{LIS}-251,129 \text { LIS }^{2}\end{array}$ & $\begin{array}{l}r^{2}=0,78 \\
r^{2}=1,00\end{array}$ \\
\hline
\end{tabular}


estão próximos aos referenciados pelo NRC (1998) de 57,64 e $18 \%$, para suínos dos 20 aos $50 \mathrm{~kg}$, porém estão acima daqueles referenciados por FONTES et al. (1997), 54 e 60\%, para metionina+cistina e treonina, respectivamente, e são equivalentes para o triptofano $(20 \%)$.

Comparando o nível de lisina, que proporcionou os melhores resultados de CA neste experimento, com os de outros trabalhos, observou-se que existe grande variação entre os valores referenciados na literatura. O nível de $1,08 \%$, estimado neste experimento, situa-se abaixo do nível de $1,26 \%$, obtido por FONTES et al. (1997), para leitoas com alto potencial genético para deposição de carne magra na carcaça, na mesma faixa de peso. Entretanto, esse valor está próximo ao nível de $1,10 \%$ de lisina obtido por LIMA et al. (1990) e acima daquele referenciado por SOUZA (1997), 0,84\%, para leitoas na fase inicial de crescimento.

A variação de resultados verificados entre os trabalhos pode estar relacionada a fatores como genótipo dos animais, sistema de alimentação, ambiente, perfil aminoacídico da ração basal, entre outros.

Com relação ao consumo de lisina médio diário (CLD), constatou-se aumento linear $(\mathrm{P}<0,01)$, em razão do crescente nível de lisina nas rações (Tabela 3). $O$ fato de o consumo de ração dos animais não ter variado significativamente pode ser justificado pelo aumento da concentração de lisina na ração. Similarmente, SOUZA (1997), avaliando níveis de lisina para leitões de 15 a $30 \mathrm{~kg}$, observou aumento linear no consumo de lisina médio dos animais.

A deposição de proteína (TDP) aumentou de forma linear $(\mathrm{P}<0,01)$ com os níveis de lisina da ração (Tabela 3). Apesar de a TDP ter aumentado de forma linear, não se constatou variação no valor absoluto deste parâmetro entre os níveis de 1,15 e $1,25 \%$ de lisina, evidenciando que a melhora no ganho de peso dos animais até o nível de 1,15\% ocorreu em razão do aumento da TDP na carcaça dos animais. Resultados semelhantes foram relatados por FONTES et al. (1997), que também observaram efeito linear dos níveis de lisina sobre a TDP na carcaça de leitoas na mesma faixa de peso.

Se a eficiência de deposição de proteína for considerada maior que a de gordura, por agregar maior quantidade de moléculas de água, pode-se também associá-la à melhora observada na CA até o nível de $1,08 \%$ de lisina, com os resultados de TDP.

\section{Experimento II - Machos inteiros}

Os resultados de desempenho, consumo de lisina médio diário e taxa de deposição de proteína média diária na carcaça de suínos, machos inteiros, estão apresentados na Tabela 2. O nível de lisina da ração influenciou de forma quadrática $(\mathrm{P}<0,05)$ o ganho de peso médio diário (GPMD) dos animais (Tabela 3), que aumentou até o nível de $1,08 \%$ de lisina total, correspondente ao consumo médio de lisina total de $15,17 \mathrm{~g} /$ dia, e $0,96 \%$ de lisina digestível verdadeira.

Este resultado foi superior ao obtido por COELHO et al. (1987a) e LIMA et al. (1990), que, trabalhando com suínos na mesma faixa de peso, verificaram melhores resultados de ganho de peso nos níveis de 1,00 e $0,94 \%$ de lisina, respectivamente. Já COELHO et al. (1991), avaliando níveis de lisina $(0,70$ a $1,10 \%)$ para leitões de 10 a $20 \mathrm{~kg}$, constataram melhora linear no ganho de peso de animais. Por outro lado, COELHO et al. (1987b), HARRISON et al. (1990) e SOUZA (1997), trabalhando com suínos na fase inicial de crescimento, não verificaram efeito do nível de lisina sobre o GPMD dos animais.

O consumo de ração médio diário (CRMD) não foi influenciado pelos tratamentos, provavelmente, em virtude de as rações serem isocalóricas. Vários trabalhos têm evidenciado que diferentes níveis de lisina na dieta não influenciaram o consumo de ração de suínos na fase inicial de desenvolvimento. COELHO et al. (1987b), estudando a exigência de lisina de suínos de 15 a $30 \mathrm{~kg}$ de peso, em rações de baixo nível protéico, observaram que a lisina teve pouco efeito sobre o consumo de ração. Todavia, LIMA et al. (1990), avaliando o efeito da idade de desmama sobre as exigências de lisina para leitões de 15 a $30 \mathrm{~kg}$ de peso, com variação no nível de lisina na ração entre 0,77 e $1,22 \%$, não constataram efeito dos tratamentos sobre o consumo de ração. Da mesma forma, HARRISON et al. (1990), COELHO et al. (1991) e SOUZA (1997), trabalhando com animais de 10 a $40 \mathrm{~kg}, 10$ a $20 \mathrm{~kg}$ e 15 a $30 \mathrm{~kg}$ de peso, respectivamente, não observaram efeito do nível de lisina sobre o consumo de ração. Já COELHO et al. (1987a), utilizando rações com nível subótimo de proteína $(15,4 \%)$, verificaram que o consumo de ração de suínos de 15 a $30 \mathrm{~kg}$ de peso diminuiu de forma linear $(\mathrm{P}<0,01)$, em razão dos níveis crescentes de lisina.

Não se observou efeito dos níveis de lisina sobre a conversão alimentar (CA). Entretanto, o nível de 
$1,05 \%$, que proporcionou o menor valor absoluto de CA $(1,81)$, pareceu o mais adequado para esses animais. Este nível situa-se acima daqueles encontrados por LIMA et al. (1990) e SOUZA (1997), 0,94 e $0,84 \%$, respectivamente. Por outro lado, está próximo ao obtido por FULLER et al. (1986), 1,07\%, para suínos dos 18 aos $45 \mathrm{~kg}$ de peso, e abaixo do nível de 1,26\% encontrado por FONTES et al. (1997), para leitoas dos 15 aos $30 \mathrm{~kg}$ de peso. Em contrapartida, COELHO et al. (1987b), trabalhando com animais mestiços de 15 a $30 \mathrm{~kg}$ de peso, não verificaram efeito dos níveis de lisina sobre a CA.

Analisando os resultados obtidos, observou-se que o mesmo nível de lisina $(1,08 \%)$ resultou em melhor desempenho tanto de leitoas, como de machos inteiros de 15 a $30 \mathrm{~kg}$, o que está de acordo com o observado por CAMPBELL et al. (1988) e COMA e ZIMMERMAN (1993), que não verificaram diferenças para valores de exigência de lisina entre suínos machos e fêmeas determinados na fase inicial. Segundo FULLER (1998), diferenças de desempenho, em função do sexo, não são evidenciadas antes dos $50 \mathrm{~kg}$, definindo-se a partir dos $70 \mathrm{~kg}$ de peso.

O consumo de lisina médio dos animais variou de forma quadrática $(\mathrm{P}<0,05)$, em razão do nível de lisina na ração, aumentando até o nível de 1,40\% (Tabela 3).

Os níveis de lisina influenciaram $(\mathrm{P}<0,01)$ a taxa de deposição de proteína (TDP) na carcaça, que variou de forma quadrática, aumentando até o nível de $1,04 \%$ (Tabela 3).

O aumento gradativo da TDP, entre os níveis de 0,85 a $1,05 \%$ de lisina, pode ser justificado pelo melhor balanceamento dos aminoácidos das rações, com a elevação do nível de lisina. CAMPBELL et al. (1988) demonstraram que, ao se manter a relação dos aminoácidos essenciais entre si, e destes com o nível de proteína da ração, é possível obter respostas positivas de composição de carcaça de leitões, mesmo com níveis de aminoácidos bem mais elevados que os recomendados pelas tabelas de exigências nutricionais de suínos (ARC, 1981).

\section{Conclusões}

Leitoas e suínos machos inteiros, da raça Landrace, dos 15 aos $30 \mathrm{~kg}$ de peso, exigem 1,08\% de lisina total ou $0,96 \%$ de lisina digestível, correspondente a um consumo de lisina total de 16,01 e 15,17 g/dia, respectivamente, para melhor desempenho.

\section{Referências Bibliográficas}

AGRICULTURAL RESEARCH COUNCIL - ARC. 1981. The nutrient requirements of pigs. Slough: Commonwealth Agricultural Bureaux. 307p.

CAMPBELL, R.G., TAVERNER, M.R., CURIC, D.M., 1988. The effects of sex and live weight on the growing pig's response to dietary protein. Anim. Prod., 46(1):123-130.

CAMPBELL, R.G., TAVERNER, M.R. 1988. Genotype and sex effects on the relationship between energy intake and protein deposition in growing pigs. J. Anim. Sci., 66:676-686.

COELHO, L.S.S., COSTA, P.M.A., PEREIRA, J.A.A. et al. 1987a. Exigências de lisina de suínos dos 15 aos $30 \mathrm{~kg}$ alimentados com rações com diferentes densidades calóricas e nível subótimo de proteína. R. Soc. Bras. Zootec., 16(1):72-80.

COELHO, L.S.S., COSTA, P.M.A., SILVA, M.A. et al. 1987b. Exigência de lisina de suínos de 15 a $30 \mathrm{~kg}$ de peso em rações de baixo nível protéico. R. Soc. Bras. Zootec., 16(1):60-71.

COELHO, L.S.S., GADELHA, J.A., BASTOS, F.J.S. et al. 1991. Exigências de lisina de suínos na fase de 10 a $20 \mathrm{~kg}$ em condições brasileiras. In: REUNIÃO ANUAL DA SOCIEDADE BRASILEIRA DE ZOOTECNIA, 28, 1991, João Pessoa, PB. Anais... João Pessoa: SBZ, p.387.

COMA, J., ZIMMERMAN, D.R., 1993. Determination of lysine requirement of growing pigs using plasma urea nitrogen in short-term trials. J. Anim. Sci., 71:60. (Suppl., 1. Abstr.).

COSCROVE, S.P., CORLEY, J.R., MAHAN, D.C. 1985. Effects of combining protein sources on lysine utilization for starter pigs. J. Anim. Sci., 60(2):470-473.

EASTER, R.A., BAKER, D.H., 1980. Lysine and protein levels in corn-soybean meals diets for growing-finishing swine. J. Anim. Sci., 50(3):467-471.

FONTES, D.O., DONZELE, J.L., CONHALATO, G.S. et al. 1997. Níveis de lisina para leitoas com alto potencial genético para deposição de carne magra, dos 15 aos $30 \mathrm{~kg}$. In: REUNIÃO ANUAL DA SOCIEDADE DE ZOOTECNIA, 34, 1997, Juiz de Fora, MG. Anais... Juiz de Fora: SBZ, p. 78-80.

FULLER, M.F. 1988. Sex differences in the nutrition and growth of pigs. In: COLE, D.J.A., HARESIGN, W. Recent developments in pig nutrition. Butterworths, (Eds.) London, UK. $321 \mathrm{p}$.

HAHN, J.D., BIEHL, R.R., BAKER, D.H. 1995. Ideal digestible lysine level for early-and late-finishing swine. J. Anim. Sci., 73(3):773-784.

HANSEN, B.C., LEWIS, A.J. 1993. Effects of dietary protein concentration (corn:soyben meal ration) on the performance and carcass characteristics of growing boars, barrows and gilts: mathematical descriptions. J. Anim. Sci., 71:2122.

HARRISON, M.D., CAMPBELL, D.R., WALKER, W.R. et al. 1990. Effects of dietary protein and crystalline lysine on performance of starting and finishing swine. Pig News Inf., 11(1):115.

LIMA, J.A.F., PEREIRA, J.A.A., COSTA, P.M.A. et al. 1990. Efeito da idade de desmama sobre as exigências de lisina para leitões na fase inicial de crescimento (15 a $30 \mathrm{~kg} \mathrm{PV})$. R. Soc. Bras. Zootec., 19(5):390-399.

MARTINEZ, G.M., KNABE, D.A. 1990. Digestible lysine requirement of starter and grower pigs. J. Anim. Sci., 68(9):2748-2755.

NATIONAL RESEARCH COUNCIL - NRC. 1988. Nutrients requirements of swine. 9 . ed. Washington, D.C.: National Academic of Science. 93p. 
Rev. bras. zootec.

NATIONAL RESEARCH COUNCIL - NRC. 1998. Nutrients requirements of swine. 10 ed. Washington, D.C.: National Academic of Science. 189p.

RHÔNE-POULENC ANIMAL NUTRITION. 1993. Rhodimet feed formulation guide. 6 ed. Rhône-Poulenc Animal Nutrition. 39p.

ROSTAGNO, H.S., SILVA, D.J., COSTA, P.M.A. et. al. 1992. Composição de alimentos e exigências nutricionais de aves e suínos (tabelas brasileiras). Viçosa, MG, Impr. Univ. 59p.

UNIVERSIDADE FEDERAL DE VIÇOSA (UFV). 1997.

S.A.E.G. (Sistema de Análises Estatísticas e Genéticas). Viçosa, MG. (Versão 7.0).

SILVA, D.J. 1990. Análise de alimentos (Métodos químicos e biológicos). Viçosa, UFV: Impr. Univ. 165p.
SOUZA, A.M. 1997. Exigências nutricionais de lisina para suínos mestiços, de 15 a $95 \mathrm{~kg}$ de peso. Viçosa, MG: UFV, 1997. 81p. Dissertação (Mestrado em Zootecnia) - Universidade Federal de Viçosa, 1997.

YEN, H.T., COLE, D.J.A., LEWIS, D. et al. 1986. Aminoacid requirements of growing pigs. 7. The response of pigs from 25 to $55 \mathrm{~kg}$ live weight to dietary ideal protein. Anim. Prod., 43(1):141-154.

Recebido em: 08/03/99

Aceito em: 26/08/99 